\title{
The pH of the Skin Surface and Its Impact on the Barrier Function
}

\author{
M.-H. Schmid-Wendtner ${ }^{a}$ H.C. Korting ${ }^{b}$ \\ Departments of Dermatology and Allergology, ${ }^{a}$ Rheinische Friedrich Wilhelm University, Bonn, and \\ ${ }^{\mathrm{b}}$ Ludwig Maximilians University, Munich, Germany
}

\section{Key Words}

Acid mantle $\cdot$ Barrier function - Skin cleansing .

Skin $\mathrm{pH} \cdot$ Synthetic detergents

\begin{abstract}
The 'acid mantle' of the stratum corneum seems to be important for both permeability barrier formation and cutaneous antimicrobial defense. However, the origin of the acidic $\mathrm{pH}$, measurable on the skin surface, remains conjectural. Passive and active influencing factors have been proposed, e.g. eccrine and sebaceous secretions as well as proton pumps. In recent years, numerous investigations have been published focusing on the changes in the $\mathrm{pH}$ of the deeper layers of the stratum corneum, as well as on the influence of physiological and pathological factors. The $\mathrm{pH}$ of the skin follows a sharp gradient across the stratum corneum, which is suspected to be important in controlling enzymatic activities and skin renewal. The skin $\mathrm{pH}$ is affected by a great number of endogenous factors, e.g. skin moisture, sweat, sebum, anatomic site, genetic predisposition and age. In addition, exogenous factors like detergents, application of cosmetic products, occlusive dressings as well as topical antibiotics may influence the skin $\mathrm{pH}$. Changes in the $\mathrm{pH}$ are reported to play a role in the pathogenesis of skin diseases like irritant contact dermatitis, atopic dermati-
\end{abstract}

tis, ichthyosis, acne vulgaris and Candida albicans infections. Therefore, the use of skin cleansing agents, especially synthetic detergents with a $\mathrm{pH}$ of about 5.5, may be of relevance in the prevention and treatment of those skin diseases.

Copyright (C) 2006 S. Karger AG, Basel

\section{Introduction}

The acidic nature of the skin surface was first determined by Heuss in 1892 [1]. Since then numerous studies have confirmed this observation. In 1928, Schade and Marchionini published their experiments on the skin $\mathrm{pH}$ using more exact biophysical methods. They introduced the 'gas chain bell electrode' adapted for the skin [2]. The acidic skin $\mathrm{pH}$ was interpreted as being due to impregnation of the horny layer with acidic constituents or eccrine sweat, because in intertriginous areas and in regions supplied by apocrine glands the reaction was less acidic or even neutral. Potentiometric measurements carried out by Blank [3] revealed skin $\mathrm{pH}$ values between 4.2 and 5.6. Since the beginning of the 1950s, the flat glass electrode was used more and more for skin $\mathrm{pH}$ measurements [4]. Schirren showed the equivalence between the plate glass electrode and the quinhydrone electrode measurement facing reproducible $\mathrm{pH}$ values around 5.2 for both meth-

\section{KARGER \\ Fax +4161306 1234 E-Mail karger@karger.ch} www.karger.com (c) 2006 S. Karger AG, Basel $1660-5527 / 06 / 0196-0296 \$ 23.50 / 0$

Accessible online at: www.karger.com/spp
Monika-Hildegard Schmid-Wendtner, MD

Department of Dermatology and Allergology, Rheinische Friedrich Wilhelm University

Sigmund-Freud-Strasse 25, DE-53105 Bonn (Germany)

Tel. +49 228287 5370, Fax +49 2282874333

E-Mail Monika-Hildegard.Schmid-Wendtner@ukb.uni-bonn.de 
Table 1. Factors influencing skin $\mathrm{pH}$ according to Rippke et al. [16], Yosipovitch and Maibach [18] and Jacobi et al. [25]

Endogenous factors
Age
Anatomic site
Genetic predisposition
Ethnic differences
Sebum
Skin moisture
Sweat
Exogenous factors
Detergents, cosmetic products, soaps
Occlusive dressings
Skin irritants
Topical antibacterials

ods [4]. On the basis of different experimental methods, Tronnier [5] suggested $\mathrm{pH}$ values closer to the alkaline range ( $\mathrm{pH}$ 6.4-6.5), while Zlotogorski [6] even more recently reported $\mathrm{pH}$ values between 4.0 and 4.9. The overall evaluation of publications which are generally recognized today suggests a surface $\mathrm{pH}$ value of the human skin (forearm of a healthy adult white male) of 5.4-5.9 [7]. However, there are 'physiological gaps in the acid barrier' which deserve special attention. This refers in particular to the axillae, the genitoanal region and the interdigital area. Due to the alkaline environment, the normal bacterial flora in these areas is considered different.

Newer results concerning factors influencing the acid mantle of the skin as well as the role of skin $\mathrm{pH}$ in different skin diseases are the subject of this review.

\section{Definition and pH Measurement}

The $\mathrm{pH}$ is defined as the negative logarithm (base ten) of the concentration of free hydrogen ions in aqueous solution. The neutral point is 7 and the maximum values of the acidic and alkaline ranges are 0 and 14, respectively. The $\mathrm{pH}$ of the extractable water-soluble components of the skin can be measured. The skin $\mathrm{pH}$ and the buffering capacity of the skin surface are made up of the contributions from all the components of the stratum corneum as well as the secretions from sebaceous and sweat glands. Today, potentiometric methods, especially with flat glass electrodes, are preferred for skin $\mathrm{pH}$ measurements, since they are more accurate compared with colorimetric methods [8].

$\mathrm{pH}$ of the Skin Surface

\section{Barrier Function}

The formation of the stratum corneum barrier involves several $\mathrm{pH}$-dependent enzymes, especially with respect to its lipophilic components and its destruction by desquamation. These hydrolases include $\beta$-glucocerebrosidase, acid sphingomyelinase, acid lipases, phosphatases and phospholipases [9]. $\beta$-Glucocerebrosidase with an optimum $\mathrm{pH}$ of 5.6 is involved in the synthesis of the most important ceramides.

At the stratum granulosum/stratum compactum interface there is a release of acid hydrolases (contents of the lamellar bodies) into the extracellular space by differentiated keratinocytes. Together with those hydrolases, glucosylceramides and phospholipids play an important role in the lamellar arrangement of barrier lipids [10]. In vitro experiments showed that the formation of lamellar structures in mixtures of horny lipids requires an acidic milieu [11]. This observation was confirmed by in vivo studies in hairless mice which showed a significantly faster recovery of the barrier function after acetone insult or adhesive film-stripping when exposed to more acidic buffer solutions [10]. Leyvraz et al. investigated the epidermal barrier function in dependence on proteolytic enzymes [12]. They regenerated mice lacking the membrane-anchored channel-activating serine protease (CAP 1) in skin, and these mice died within $60 \mathrm{~h}$ after birth. Besides a lower body weight they exhibited severe malformation of the stratum corneum, which was accompanied by an impaired skin barrier function. As evidenced by dehydration and skin permeability assay and transepidermal water loss measurements, this resulted in a rapid and fatal dehydration [12].

Various investigations revealed that low $\mathrm{pH}$ values in the extracellular space play an important role in the regulation of enzyme activity, especially in keratinization and barrier regeneration [13-15]. In this respect, acidic buffer substances applied topically may contribute to the maintenance of the normal barrier function of the skin.

\section{Factors Affecting Skin pH}

The $\mathrm{pH}$ of the skin surface can be influenced by a number of endogenous (physiological) and exogenous factors [16-18]. The most important of these (table 1) are discussed in more detail.

Age has long been known to influence the skin $\mathrm{pH}$. Previous studies indicated that the skin undergoes a process of adaptation and maturation postnatally. In recent

Skin Pharmacol Physiol 2006;19:296-302 
years, experimental studies especially focused on infants, small children and the elderly. Visscher et al. [19] reported relatively neutral surface $\mathrm{pH}$ values in neonates with a decrease to about 5.5 over the first 4 postnatal days. These data were confirmed by Yosipovitch et al. [20] who measured elevated initial mean $\mathrm{pH}$ values of 7.08 (SD 0.17 ) with significant decreases of $\mathrm{pH}$ by day 2 . Hoeger and Enzmann [21] assessed skin function parameters (skin surface $\mathrm{pH}$, corneal layer hydration, epidermal desquamation, and surface roughness) prospectively in a cohort of 202 healthy term neonates. They found a decrease in surface $\mathrm{pH}$ by $0.3-1.1$ units, while desquamation increased significantly during the observation period (12 weeks). In addition, stratum corneum hydration increased significantly, paralleled by a decrease in skin roughness [21]. Data concerning the skin $\mathrm{pH}$ of schoolchildren are inhomogeneous. There might be a reduced resistance to alkaline noxae despite an unremarkable basal $\mathrm{pH}$. In contrast, both an increased skin surface $\mathrm{pH}$ and a reduced buffer capacity have been documented for skin of the elderly [22]. In the 18-60-year age group, the skin surface $\mathrm{pH}$ remains constant in most anatomical sites [22].

Comparing data obtained from different anatomical sites may often be inappropriate because skin surface composition is not necessarily uniform and hygiene habits may be totally different depending on the body area. However, it is generally accepted that skin surface $\mathrm{pH}$ is relatively similar at different body sites except in areas with higher moisture: the intertriginous areas (the axilla, inguinal and submammary folds and finger webs) have a slightly higher $\mathrm{pH}$ than other body areas [7, 23].

Skin $\mathrm{pH}$ has occasionally been reported to vary with ethnic and genetic background. However, racial differences in skin have been minimally investigated by objective methods. It has been demonstrated that people with black skin have a lower skin surface $\mathrm{pH}$ than people with white skin [24]. The assumption that brown-skinned individuals from India might have a slightly different skin surface $\mathrm{pH}$ compared with Europeans has not yet been proven by exact statistical methods [17]. Studies concerning gender-related differences in skin physiology provided conflicting results. A newer investigation involving 6 female and 6 male volunteers revealed a higher $\mathrm{pH}$ for women $(5.6 \pm 0.4)$ than for men $(4.3 \pm 0.4, \mathrm{p}<0.05)$ [25].

The sebum of the skin has a moderate effect on the $\mathrm{pH}$ to be measured. The effect depends on the amount of sebum. For example, a high sebum content on the forehead in a patient with acne vulgaris may artificially affect the $\mathrm{pH}$ measurement. Skin $\mathrm{pH}$ also depends on skin mois- ture: areas with higher moisture such as the axilla and inguinal regions have a higher $\mathrm{pH}$.

In historic reports, differences in sweat $\mathrm{pH}$ according to the sweating intensity are reported [26]. Until today there is no confirmation that thermal sweat, sweat from covered body areas and sweat from eccrine glands really is more acidic than sweat from effort, air-exposed skin areas and apocrine glands.

There are numerous external factors affecting the measured skin surface $\mathrm{pH}$. One of the most important ones is skin cleansing. A pH rise for few hours at least is observed after cleansing the skin with alkaline soaps $(\mathrm{pH}$ 10.5-11.0). The use of synthetic detergents formulated at the same $\mathrm{pH}$ as skin and even tap water also leads to a rise of the skin surface $\mathrm{pH}$, however to a lesser extent and for a shorter period of time [27, 28]. It is assumed that such temporary skin $\mathrm{pH}$ changes are limited to the uppermost layers of the stratum corneum, which was examined using the tape-stripping method [17]. About 15 years ago, Korting et al. [29, 30] were one of the first groups who examined the effect of different skin cleansing methods in healthy volunteers focusing on the bacterial flora and the skin surface $\mathrm{pH}$. In a clinical crossover study one half of the healthy volunteers washed their foreheads and forearms twice daily for $1 \mathrm{~min}$ with soap, the other volunteers washed with a syndet with an acidic $\mathrm{pH}$. After 4 weeks, the respective other skin cleansing agent was used for the next 4 weeks. At the beginning of the study and at the end of every week, skin $\mathrm{pH}$ and density of the bacterial flora were determined [29]. When soap was used first, the $\mathrm{pH}$ increased. After change-over to the syndet the $\mathrm{pH}$ dropped. When the syndet was applied first, the $\mathrm{pH}$ dropped slightly, but after changing to soap it increased to values above the initial values [29]. Statistical evaluations showed that the $\mathrm{pH}$ values were about 0.3 units lower in the case of long-term application of the acidic syndet. However, after individual washing, both the soap and the syndet led to a short-term increase in $\mathrm{pH}$, which regressed within a few hours [26]. After repeated soap washing, the count of propionibacteria increased strongly and dropped after repeated syndet application. Moreover, for the forehead a correlation could be established between germ species and the skin surface $\mathrm{pH}$ [29]. Various topical products, for example deodorants, have been reported to affect the skin surface $\mathrm{pH}$, at least for a few hours $[31,32]$. The effects of occlusive dressings on the skin surface $\mathrm{pH}$ have been known for several decades. Hartmann [33] demonstrated a significant increase in the skin surface $\mathrm{pH}$ in healthy volunteers after 3 days of occlusion with a return to the baseline $\mathrm{pH}$ 
value only 1 day after removal of the occlusive dressing. Elsner and Maibach [34] reported a significant decrease in the skin $\mathrm{pH}$ after drying of primary occluded skin of the vulva, associated with a significant reduction of the transepidermal water loss. This was explained by an increased ion permeability of the stratum corneum because of occlusion, resulting in neutralization of the acidic skin surface [34]. In addition, a delay in restoration of the barrier function after occlusive acetone treatment was described associated with a rise in the skin surface $\mathrm{pH}$ [35].

\section{Skin pH in Diseases}

Both lipid organization and lipid metabolism in the stratum corneum require an acidic $\mathrm{pH}$. Alterations in those processes contribute to the disturbance of skin barrier function observed in different skin diseases. Today we know that a disturbed stratum corneum skin $\mathrm{pH}$ has important clinical implications in several clinical situations, for example in psoriasis and atopic dermatitis [36] as well as in more rare dermatoses like the Netherton syndrome [37]. Frequent skin diseases with disturbed skin $\mathrm{pH}$ are discussed in more detail below.

\section{Atopic Dermatitis}

Several pathogenetic and therapeutically relevant factors in atopic dermatitis can be affected by changes in skin surface $\mathrm{pH}$. Besides genetic and immunologic factors, skin dryness caused by a disturbance of skin barrier function and microbial colonization may play an important role. About 50 years ago there was initial evidence for an altered skin surface $\mathrm{pH}$ in patients with atopic dermatitis. Epprecht [38], for example, described elevated $\mathrm{pH}$ values of the skin surface, with slower alkaline neutralization, in patients with acute disseminated atopic dermatitis. Schnyder et al. [39] determined a reduced alkaline resistance in $83 \%$ of patients with atopic dermatitis compared with $17 \%$ of those with healthy skin. These early data have been confirmed in recent years by numerous systematic studies, using planar glass electrodes for pH measurement [40, 41].

Seidenari and Giusti [41] showed that the $\mathrm{pH}$ values measured in eczematous and in clinically uninvolved skin areas were significantly higher in patients with atopic dermatitis than those in healthy children. In addition, the $\mathrm{pH}$ values in eczematous skin areas were significantly higher than in unaffected areas, which in turn were significantly higher in patients with clinical findings than in patients in a symptom-free interval [41]. These findings were corroborated by Sparavigna et al. [42], who compared the cutaneous $\mathrm{pH}$ of 143 children with atopic dermatitis and 141 healthy children, aged 3 months to 11 years. They reported a progressive decrease in $\mathrm{pH}$ values from lesional to perilesional to unaffected skin sites, and to corresponding skin sites of healthy children [42]. Eberlein-König et al. [40] examined 377 primary schoolchildren for skin surface $\mathrm{pH}$, stratum corneum hydration, transepidermal water loss and skin roughness. Only the skin $\mathrm{pH}$ differed significantly, with higher mean values in the 45 children with atopic dermatitis compared with the healthy children. Furthermore, an elevated $\mathrm{pH}$ could be correlated with the severity of dryness and itching [40].

Whereas the significance of free fatty acids for the alterations of $\mathrm{pH}$ in atopic skin remains inconclusive [43], recent findings suggest that urocanic acid may play a key role in maintenance of the acidic $\mathrm{pH}$ of the stratum corneum [44]. According to the authors, urocanic acid is produced from histidine by a self-regulated control cycle, involving the $\mathrm{pH}$-dependent activity of the enzyme histidase for the maintenance of moisture content and $\mathrm{pH}$ of the stratum corneum. Other studies confirmed a significant reduction in urocanic acid and suggested a diminished histidase activity in atopic skin [45].

\section{Irritant Contact Dermatitis}

The $\mathrm{pH}$ of the skin surface can also be used to predict the risk of individuals without atopic background to develop irritant contact dermatitis. Wilhelm and Maibach [46] compared several skin parameters in 10 healthy volunteers before and after inducing skin irritation with $1 \%$ sodium lauryl sulphate. The authors reported significant correlations for the surface $\mathrm{pH}$, the $\mathrm{pH}$ of the deeper stratum corneum layers exposed after five tape strippings, but not for the transepidermal water loss, sebum content or renewal rate of the horny layer [46]. These findings were confirmed by the group of Francomano [47] who observed higher $\mathrm{pH}$ values of the cheeks in patients with sensitive skin objectively prone to skin irritations, than in healthy volunteers. Disturbances of the skin $\mathrm{pH}$ play a pathogenetic role in infants, too. Ammonia-induced alkalinization activates stool enzymes such as lipase and trypsin, leading to irritation and disruption of the skin barrier, where the skin has been reported in some cases to already have an elevated baseline $\mathrm{pH}$ of $6.6[48]$.

Skin Pharmacol Physiol 2006;19:296-302 


\section{Ichthyosis}

Öhman and Valquist [49] compared the $\mathrm{pH}$ gradients of the horny layer of patients with X-chromosomal recessive ichthyosis and autosomal dominant ichthyosis vulgaris with those of healthy volunteers. The $\mathrm{pH}$ on the skin surface in patients with ichthyosis vulgaris was significantly higher $(5.3, \mathrm{SD} 0.7)$ than in patients with X-chromosomal recessive ichthyosis (4.6, SD 0.4), and was higher than the $\mathrm{pH}$ of healthy skin (4.5, SD 0.2). A neutral pH was reached in patients with ichthyosis vulgaris after half the horny layer had been removed using the tape stripping method. In contrast, in patients with X-chromosomal recessive ichthyosis, a plateau $\mathrm{pH}$ value of 6.2-6.6 was never exceeded even in the lower stratum corneum. It was concluded that in patients with ichthyosis vulgaris there is a congenital deficiency of acid degradation products of filaggrin, whereas in patients with X-chromosomal recessive ichthyosis there is an accumulation of cholesterol sulphate in the lower horny layer induced by a lack of steroid sulphatase, leading to a flattening of the $\mathrm{pH}$ gradient [49]. As a result, pH-dependent enzymes involved in desquamation of the skin may be disturbed. Reduced filaggrin formation levels have been confirmed in patients with ichthyosis vulgaris, lamellar ichthyosis and congenital ichthyosiform erythrodermia [50]. The steep amino acid gradient, with high values in the deep horny layer of healthy skin, is much flatter in ichthyosis vulgaris. This might explain the advantage of special acidic topical preparations containing lactic acid for keratolysis in patients with ichthyosis vulgaris.

\section{Fungal Infections in Special Patient Populations}

Yosipovitch et al. [51] compared skin surface $\mathrm{pH}$ and moisture in intertriginous areas in 50 non-insulin-dependent diabetic patients and healthy volunteers. They measured significantly higher $\mathrm{pH}$ values in the intertriginous skin areas of these patients (but not on the forearms) compared with the healthy control group. This was interpreted as a risk factor for the development of candida mycoses [51]. In another investigation, a significant increase in the skin $\mathrm{pH}$ in patients on dialysis was reported [52]. The changes observed, relating to the tendency to develop mycotic skin infections, were considered to have clinical relevance [52]. In an experimental setting, Candida albicans cell suspension, buffered either at $\mathrm{pH} 6.0$ or 4.5 , was applied to healthy skin under occlusion. After $24 \mathrm{~h}$, there were significantly less mycotic skin lesions at the acidic site, which confirms the relevance of an intact acidic milieu for the patient's defense capability against fungal infections [53].

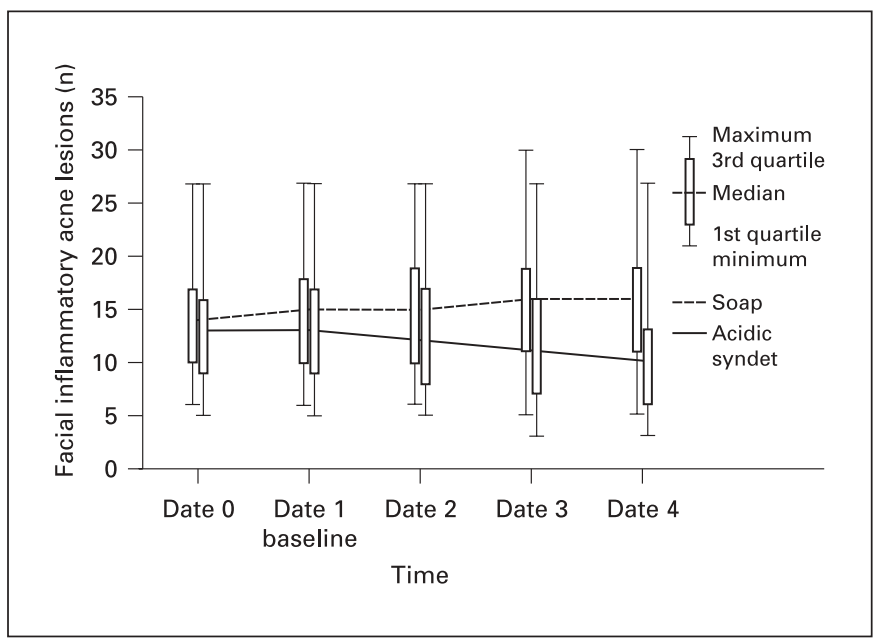

Fig. 1. Number of facial inflammatory acne lesions in a comparative trial with 3-month application of either soap or acidic syndet (from Korting et al. [57], with permission).

\section{Skin pH and Skin Cleansing}

Even rinsing the skin with water alone immediately produces a transient increase in the skin $\mathrm{pH}$ [54]. Washing the hands with conventional soap causes the $\mathrm{pH}$ on the palms to increase by an average of 3 units. Even 90 min after washing with soap the $\mathrm{pH}$ of the hands was not completely normalized [55]. However, soaps were used for over thousands of years for regular skin cleansing, while synthetic cleansers of the liquid or the bar type have started to become an alternative just about 30 years ago. Keining [56] was the first to describe the advantages of the so-called syndets. He mentioned a decreased irritancy potential, lack of sensitization and capability to maintain or even restore the acid mantle of the skin [56]. Today, the value of acidic syndets in the therapy of various skin diseases is widely accepted on clinical grounds. For quite a while, a close relationship has been postulated between skin surface $\mathrm{pH}$ and its microbial flora (transient and resident). Bacteria can grow over a wide $\mathrm{pH}$ range, but no microorganisms will grow equally at all $\mathrm{pH}$ values. Most grow better at a $\mathrm{pH}$ around neutrality. Acidic $\mathrm{pH}$ could be bacteriostatic for some strains. Korting et al. [57], for example, investigated the influence of the regular use of a soap or an acidic syndet bar on acneprone patients. In a randomized, open-labeled, comparative trial the 3-month application of either skin cleansing preparation to facial skin for $1 \mathrm{~min}$ each in the morning and in the evening was compared in 120 adolescents and young adults with inflammatory acne I or II accord- 
ing to the Plewig and Kligman classification [57]. The number of inflammatory acne lesions, i.e. papulopustules, differed in the two trial groups from 4 weeks of application onward. In the group using soap the mean number of inflammatory lesions increased from 14.6 (SD 5.3) to 15.3 (SD 6.0), while it decreased in the other group from 13.4 (SD 5.2) to 10.4 (SD 5.8; $\mathrm{p}<0.0001$; fig. 1). Acidic syndet bars, in addition, showed a better tolerability. The authors concluded that acidic cleansers should be preferred for skin care in acne-prone adolescents and young adults.

Just recently, the impact of acidic hand cleansers for prevention of rhinovirus infections has been investigated, since direct hand-to-hand contact is an important mechanism of transmission of rhinovirus infection [58]. Hands of volunteers were contaminated with rhinovirus at defined times ( $15 \mathrm{~min}, 1 \mathrm{~h}$ and $3 \mathrm{~h}$ ) after use of acidic hand cleansers (containing salicylic acid and/or pyroglutamic acid). Then volunteers attempted to inoculate the nasal mucosa with one hand while quantitative viral cultures were done on the other hand. Virus was recovered from the hands in $90 \%$ of the volunteers in the control group compared with $15 \%$ in the groups who used acidic hand cleansers after $15 \mathrm{~min}$. Rhinovirus infection occurred in $32 \%$ of patients in the control group and in only $7 \%$ of patients in the treatment groups. The authors suggested the feasibility of the prevention of rhinovirus transmission by acidic hand treatments that are virucidal on contact and have activity that persists after application [58].

\section{Conclusion}

A central role for the acidic milieu as a regulating factor in stratum corneum homeostasis was postulated. This has relevance for the integrity of the barrier function, from normal maturation of the stratum corneum lipids through to desquamation. An elevated skin $\mathrm{pH}$ may also influence the activity of the enzymatic process of lipid metabolism in the stratum corneum, which might contribute to a dramatic skin barrier anomaly observed, for example, in atopic dermatitis. In addition, changes in skin $\mathrm{pH}$ become clinically significant because of the creation of a favorable environment for the growth of bacteria, especially Staphylococcus aureus. Because of their bacteria-regulating properties and favorable tolerability profile, syndets with an acidic $\mathrm{pH}$ are now preferred for skin cleansing in patients with seborrheic-type diseases (acne vulgaris, rosacea), atopic skin diathesis, irritant contact dermatitis and ichthyosis. Moreover, special populations such as diabetic patients or patients on dialysis may profit from washing with acidic syndets because the occurrence of fungal infections may be reduced. There is good reason to believe that acidic syndets are of value even for persons with healthy skin, for example to prevent rhinovirus transmission and infection.

\section{References}

1 Heuss E: Die Reaktion des Schweisses beim gesunden Menschen. Monatschr Prakt Dermatol 1892;14:341-343.

2 Schade H, Marchionini A: Der Säuremantel der Haut (nach Gaskettenmessung). Klin Wochenschr 1928; 7:12-14.

3 Blank HI: Measurement of $\mathrm{pH}$ of the skin surface. J Invest Dermatol 1939;2:67-79.

4 Schirren CG: Does the glass-electrode determine the same $\mathrm{pH}$ values on the skin surface as a quinhydrone electrode? J Invest Dermatol 1955;24:485-488.

5 Tronnier A: Seifen und Syndets in der Hautpflege und Therapie. Ärztl Kosmetol 1985;15: 19-30.

6 Zlotogorski A: Distribution of skin surface $\mathrm{pH}$ on the forehead and cheek of adults. Arch Dermatol Res 1987;398-401.

7 Braun-Falco O, Korting HC: Der normale $\mathrm{pH}-$ Wert der Haut. Hautarzt 1986;37:126-129.
8 Dikstein S, Zlotogorski A: Measurements of skin pH. Acta Derm Venereol (Stockh) 1994;(suppl 185):18-20.

9 Redoules D, Tarroux R, Perie J: Epidermal enzymes: their role in homeostasis and their relationship with dermatoses. Skin Pharmacol Appl Skin Physiol 1998;11:183-192.

10 Mauro T, Holleran WM, Grayson S, et al: Barrier recovery is impeded at neutral $\mathrm{pH}$, independent of ionic effects: implications for extracellular lipid processing. Arch Dermatol Res 1998;290:215-222.

11 Bouwstra JA, Gooris GS, Dubhelaar FER, et al: $\mathrm{pH}$, cholesterol sulfate, and fatty acids affect the stratum corneum lipid organization. J Invest Dermatol 1998;3:69-74.

12 Leyvraz C, Charles RP, Rubera I, et al: The epidermal barrier function is dependent on the serine protease CAP 1/Prss8. J Cell Biol 2005; 170:487-496.
13 Vahlquist A: Variations in skin $\mathrm{pH}$ during normal and pathological keratinisation. Retinoids 1999; 139:855-857.

14 Fluhr JW, Kao J, Jain M, et al: Generation of free fatty acids from phospholipids regulates stratum corneum acidification and integrity. $\mathrm{J}$ Invest Dermatol 2001;117:44-51.

15 Elias P: Stratum corneum architecture, metabolic activity and interactivity with subjacent barrier function. Br J Dermatol 1996;5:191201.

16 Rippke F, Schreiner V, Schwanitz HJ: The acidic milieu of the horny layer. New findings on the physiology and pathophysiology of skin pH. Am J Clin Dermatol 2003;3:261-272.

17 Parra JL, Paye M: EEMCO guidance for the in vivo assessment of skin surface $\mathrm{pH}$. Skin Pharmacol Appl Skin Physiol 2003;16:188-202.

18 Yosipovitch G, Maibach HI: Skin surface pH: a protective acid mantle. Cosmet Toiletries 1996;111:101-102. 
19 Visscher MO, Chatterjee R, Munson KA, et al: Changes in diapered and non-diapered infant skin over the first month of life. Pediatr Dermatol 2000; 17:45-51.

20 Yosipovitch G, Maayan-Metzger A, Merlob P, et al: Skin barrier properties in different body areas in neonates. Pediatrics 2000;106:105108.

21 Hoeger PH, Enzmann CC: Skin physiology of the neonate and young infant: a prospective study of functional skin parameters during early infancy. Pediatr Dermatol 2002;19:256262.

22 Zlotogorski A: Distribution of skin surface $\mathrm{pH}$ on the forehead and cheek of adults. Arch Dermatol Res 1987;279:398-401.

23 Dikstein S, Zlotogorski A: Skin surface hydrogen ion concentration $(\mathrm{pH})$; in Leveque $\mathrm{JL}$ (ed): Cutaneous Investigation in Health and Disease. New York, Marcel Dekker, 1989, pp 59-77.

24 Naissan O, Maibach W, Maibach HI: Racial (ethnic) differences in skin properties. Am J Clin Dermatol 2003;4:843-860.

25 Jacobi U, Gautier J, Sterry W, et al: Genderrelated differences in the physiology of the stratum corneum. Dermatology 2005;211:312317

26 Talbert GA: Effect of work and heat on the hydrogen-ion concentration of the sweat. Am J Physiol 1919;50:433.

27 Korting HC, Braun-Falco O: The effects of detergents on skin $\mathrm{pH}$ and its consequences. Clin Dermatol 1995;14:23-27.

28 Barel AO, Lambrecht R, Clarys P, et al: A comparative study of the effects on the skin of a classical bar soap and a syndet cleansing bar in normal use conditions and in the soap chamber test. Skin Res Technol 2001;7:98-104.

29 Korting HC, Kober M, Müller M, et al: Influence of repeated washings with soap and synthetic detergents on $\mathrm{pH}$ and resident flora of the skin of forehead and forearm. Results of a cross-over trial in health probationers. Acta Derm Venereol (Stockh) 1987;67:41-47.

30 Korting HC, Greiner K, Hübner K, et al: Changes in the skin $\mathrm{pH}$ and resident flora by washing with synthetic detergent preparations at pH 5.5 and 8.5. J Soc Cosmet Chem 1991; 42:147-158.

31 Stenzaly-Achtert S, Schölermann A, Schreiber $\mathrm{J}$, et al: Axillary $\mathrm{pH}$ and influence of deodorants. Skin Res Technol 2000;6:87-91.

32 Wickett RR, Trobaugh CM: Personal care products: effect on skin surface $\mathrm{pH}$. Cosmet Toilet 1990;105:41-46.

33 Hartmann AA: Effect of occlusion on resident flora, skin-moisture and skin-pH. Arch Dermatol Res 1983;275:251-254
34 Elsner P, Maibach HI: The effect of prolonged drying on transepidermal water loss, capacitance and $\mathrm{pH}$ of human vulvar and forearm skin. Acta Derm Venereol (Stockh) 1990;70: 105-109.

35 Schreiner V, Maerker U, Hoppe U: Dependence of barrier repair in human skin on intraand extracellular pH. J Invest Dermatol 1996; 106:917.

36 Farwanah H, Raith K, Neubert RH, et al: Ceramide profiles of the uninvolved skin in atopic dermatitis and psoriasis are comparable to those of healthy skin. Arch Dermatol Res 2005; 296:514-512.

37 Chao SC, Richard G, Lee JY: Netherton syndrome: report of two Taiwanese siblings with staphylococcal scaled skin syndrome and mutation of SPINK5. Br J Dermatol 2005;152: 159-165.

38 Epprecht R: Elektrometrische Messungen mit besonderer Berücksichtigung der Säureneutralisation. Dermatologica 1955; 111:204223.

39 Schnyder UW, Gloor M, Taugner M: Über die sozialmedizinische Bedeutung von Alkaliresistenz, Alkalineutralisation und Hautoberflächenlipidmenge bei Neurodermitis atopica und Ichthyosis vulgaris. Berufsdermatosen 1977;25:101-140

40 Eberlein-König B, Schäfer T, Huss-Marp J, et al: Skin surface $\mathrm{pH}$, stratum corneum hydration, trans-epidermal water loss and skin roughness related to atopic eczema and skin dryness in a population of primary school children. Acta Derm Venereol (Stockh) 2000;80: 188-191.

41 Seidenari S, Giusti G: Objective assessment of the skin of children affected by atopic dermatitis and in healthy children: a multicenter study. Acta Derm Venereol (Stockh) 1995;75: 429-433.

42 Sparavigna A, Setaro M, Gualandri V: Cutaneous $\mathrm{pH}$ in children affected by atopic dermatitis and in healthy children: a multicenter study. Skin Res Technol 1999;5:221-227.

43 Hara J, Higuchi K, Okamoto R, et al: Highexpression of sphingomyelin deacylase is an important determinant of ceramide deficiency leading to barrier disruption in atopic dermatitis. J Invest Dermatol 2000;115:406-413.

44 Krien PM, Kermici M: Evidence for the existence of a self-regulation enzyme process within the human stratum corneum: an unexpected role for urocanic acid. J Invest Dermatol 2000 115:414-420.

45 Abeck D, Lauer W, Schmidt T, et al: Age-dependent differences of histidine urocanic acid and urocanic isomers concentration in atopic eczema (abstract). J Invest Dermatol 1996; 107:468
46 Wilhelm KP, Maibach HI: Susceptibility to irritant dermatitis induced by sodium lauryl sulphate. J Am Acad Dermatol 1990;23:122124

47 Francomano MA, Mantovani L, Pepe P, et al: Baseline biophysical parameters in subjects with sensitive skin (abstract). Skin Res Technol 1996;2:225.

48 Gfatter R, Hackl P, Braun F: Effects of soap and detergents on skin surface $\mathrm{pH}$, stratum corneum hydration and fat content in infants. Dermatology 1997;195:258-262.

49 Öhmann H, Vahlquist A: The pH gradient over the stratum corneum differs in X-linked recessive and autosomal dominant ichthyosis: a clue to the molecular origin of the acid skin mantle? J Invest Dermatol 1998;111:674677

50 Menon GK, Ghadially R, Williams ML, et al: Lamellar bodies as delivery systems of hydrolytic enzymes: implications for normal and abnormal desquamation. Br J Dermatol 1992; 126:337-345.

51 Yosipovitch G, Tur E, Cohen O, et al: Skin surface $\mathrm{pH}$ in intertriginous areas in non-insulin-dependent diabetes mellitus patients. Diabetes Care 1993;16:560-563.

52 Yosipovitch G, Tur E, Morduchowitz G, et al: Skin surface $\mathrm{pH}$, moisture, and pruritus in haemodialysis patients. Nephrol Dial Transplant 1993;8:1129-1132.

53 Runeman B, Faergemann J, Larkö O: Experimental Candida albicans lesions in healthy humans: dependence on skin $\mathrm{pH}$. Acta Derm Venereol 2000;80:421-424.

54 Gfatter R, Hackl P, Braun F: Effects of soap and detergents on skin surface $\mathrm{pH}$, stratum corneum hydration and fat content in infants. Dermatology 1997; 195:258-262.

55 Mücke H, Mohr KT, Rümmler A, et al: Untersuchungen über den Haut-pH-Wert der Hand nach Anwendung von Seife, Reinigungs- und Händedesinfektionsmitteln. Pharmazie 1993; 48:468-469.

56 Keining E: Zur Frage der Reinigung gesunder und kranker Haut. Dermatol Wochenschr 1959;46:1245-1251.

57 Korting HC, Ponce-Pöschl E, Klövekorn W, et al: The influence of the regular use of a soap or an acidic syndet bar on pre-acne. Infection 1995;23:89-93.

58 Turner RB, Biedermann KA, Morgan JM, et al: Efficacy of organic acids in hand cleansers for prevention of rhinovirus infections. Antimicrob Agents Chemother 2004;46:25952598 